\title{
Espaçamentos entrelinhas e entre plantas no crescimento e na produção de repolho roxo
}

\author{
Gilson Silverio da Silva ("); Arthur Bernardes Cecílio Filho; José Carlos Barbosa; \\ Anarlete Ursulino Alves \\ Universidade Estadual Paulista "Julio de Mesquita Filho" (UNESP), Faculdade de Ciências Agrárias e Veterinárias (FCAV), \\ Departamento de Produção Vegetal, Rodovia Paulo Donato Castellane s/n, 14884-900 Jaboticabal (SP). \\ (") Autor correspondente: silverios@hotmail.com
}

Recebido: 18/mai./2010; Aceito:22/set./2010.

\section{Resumo}

Um experimento foi realizado no período de 19 de maio a 17 de setembro de 2008, em Jaboticabal (SP), com o objetivo de avaliar o efeito de espaçamentos entrelinhas e entre plantas sobre o crescimento e a produtividade do repolho roxo. 0 experimento foi instalado sob delineamento de blocos ao acaso, com os tratamentos em esquema fatorial $4 \times 3$ e três repetições. Foram avaliados os espaçamentos entrelinhas 0,40; 0,60; 0,80 e 1,0 m e os espaçamentos entre plantas 0,30; 0,40 e 0,50 m. Com menores espaçamentos entrelinhas e/ou entre plantas houve redução do número de folhas, da área foliar, massa seca das folhas externas e massa fresca da "cabeça", enquanto o índice de área foliar e a produtividade aumentaram. A maior produtividade $\left(4,56 \mathrm{~kg} \mathrm{~m}^{-2}\right)$ foi estimada no espaçamento 0,60 m entrelinhas e 0,30 m entre plantas.

Palavras-chave: Brassica oleracea var. capitata, densidade populacional, população de plantas.

\section{Growth and yield of red cabbage as affected by distances between rows and plants}

\section{Abstract}

An experiment was carried out from May 19 to September 17, 2008, in Jaboticabal, State of São Paulo, Brazil, with the aim of evaluating the effects of spacing between rows $(0.4,0.6,0.8$ and $1.0 \mathrm{~m})$ and between plants $(0.3,0.4$ and $0.5 \mathrm{~m})$ on the growth and yield of cabbage. The experimental design was a randomized complete block with treatments in a factorial scheme $4 x$ 3 , and three replications. Small spacing between rows or between plants reduced the number of leaves, leaf area, dry matter of leaves and head fresh weight, whereas the leaf area index and yield increased. The highest yield $\left(4.56 \mathrm{~kg} \mathrm{~m}^{-2}\right)$ was obtained with $0.6 \mathrm{~m}$ between rows and $0.3 \mathrm{~m}$ between plants.

Key words: Brassica oleraceae var. capitata, population density, plant population.

\section{INTRODUÇÃO}

Entre as várias hortaliças ofertadas aos consumidores brasileiros, o repolho é a hortaliça de maior importância econômica entre as variedades botânicas da espécie Brassica oleracea. Recentemente, foram disponibilizadas cultivares de repolho roxo, cuja aceitação pelo consumidor foi boa. Em 2007, foram comercializados na Companhia de Entrepostos e Armazéns Gerais do Estado de Sáo Paulo - CEAGESP ${ }^{(1)}$ cerca de 4 mil toneladas de repolho roxo, enquanto na CEASAMINAS $\left(^{2}\right)$ foram 1,4 mil toneladas.

Dentre os vários fatores de produção a serem estudados para as novas cultivares disponíveis no mercado, tem-se o espaçamento. De modo geral, estudos sobre espaçamentos visam maximizar a população de plantas por unidade de área, pois, dentre as vantagens do adensamento têm-se: redução da infestação do cultivo por plantas daninhas, do tamanho do produto a ser comercializado e do ciclo; e aumento da cobertura e proteção do solo; da eficiência no aproveitamento de insumos aplicados (fertilizantes e agrotóxicos) e recursos disponíveis (água, luz e solo) e de produtividade. Contudo, as vantagens encerram-se quando se atinge o ponto de competição. Conforme Mendonza (1982) e Choairy e Fernandes (1983), a partir desse ponto densidades elevadas podem causar, além de reduçóes na produtividade, seja por menor espaço disponível às plantas, seja

(1) LOPES, A.P. CEAGESP. Seção de Economia e Desenvolvimento. Av. Dr. Gastão Vidigal, I946, Vila Leopoldina, o 53 I 6-900 São Paulo (SP).

(²) MARTINS, R.F. CEASAMINAS GRANDE BELO HORIZONTE, SEEST/DETEC, BR o40, Km 688, 32 I 45-900 Bairro Guanabara, Contagem (MG). 
por maior severidade no ataque de pragas e doenças, perdas na qualidade, como modificaçôes no tamanho e na forma, constatadas em hortaliças folhosas.

$\mathrm{Na}$ literatura há relatos de efeitos de espaçamentos entre plantas e/ou entrelinhas em muitas hortaliças, inclusive para repolho. Contudo, para cultivares de repolho roxo, recentemente disponibilizadas aos produtores e que vem aumentando a aceitação por consumidores, raríssimos estudos foram realizados.

ARAújo (1975) avaliou duas cultivares sob cinco populaçôes (18.857 a 41.667 plantas ha $^{-1}$ ), obtidas de combinaçóes de um espaçamento entrelinhas de $0,80 \mathrm{~m}$ e cinco entre plantas $(0,30 ; 0,40 ; 0,50 ; 0,60$ e $0,70 \mathrm{~m})$ e outras cinco populações (25.571 a 66.667 plantas ha $\left.^{-1}\right)$, resultantes de um espaçamento entrelinhas de $0,50 \mathrm{~m}$ e cinco entre plantas $(0,30 ; 0,40 ; 0,50 ; 0,60$ e $0,70 \mathrm{~m})$. O comprimento do coração e o ciclo não foram afetados pelas populaçóes de plantas, enquanto o número de folhas externas e a massa da "cabeça" foram reduzidas e a produtividade aumentou à medida que maior foi a população de plantas. Resultados semelhantes para repolho verde foram observados por Stoffella e Fleming (1990), Aquino et al. (2005) e CAVArianni (2008).

Devido à escassez de pesquisas, os espaçamentos recomendados para o repolho roxo baseiam-se em indicaçóes feitas para o repolho tradicional, ou verde. Somente foi verificado um trabalho entre as literaturas consultadas que avaliou o efeito de espaçamentos na cultura do repolho roxo. CAVArianni (2008), avaliando a interação existente entre densidades populacionais $(31.250$ e 46.875 plantas ha $\left.{ }^{-1}\right)$ e doses de nitrogênio ( 0 a $\left.300 \mathrm{~kg} \mathrm{ha}^{-1}\right)$ sobre o desenvolvimento e a produtividade de repolho roxo, observou que a massa fresca não foi influenciada pela densidade de plantio. Porém, com a população de 46.875 plantas $\mathrm{ha}^{-1}$ obteve-se produtividade de $23,8 \mathrm{t} \mathrm{ha}^{-1}$, enquanto na população de 31.250 plantas ha ${ }^{-1}$ a produtividade foi de $17,5 \mathrm{t} \mathrm{ha}^{-1}$.

Diante dos resultados disponíveis na literatura verificase que fisiologicamente a planta de repolho é influenciada pelo espaçamento entrelinhas e/ou entre plantas. A intensidade da competição intraespecífica estabelecida pelo manejo do espaçamento/densidade populacional causa modificaçôes na planta, que repercutem tanto na produtividade da cultura, quanto na qualidade do repolho colhido e, consequentemente, na rentabilidade do cultivo.

O presente trabalho teve como objetivo avaliar o efeito de espaçamentos entrelinhas e entre plantas sobre o crescimento e a produtividade do repolho roxo.

\section{MATERIAL E MÉTODOS}

O experimento foi realizado de 19-5 a 17-9-2008, em Ja-

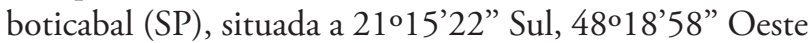
e altitude de 575 metros. Durante o período experimental as médias das temperaturas máxima, média e mínima foram, respectivamente, de 28,$3 ; 20,2$ e $14,2{ }^{\circ} \mathrm{C}$ e a umidade relativa do ar média foi de $64,9 \%$.

Foram avaliados 12 tratamentos, que resultaram da combinação dos fatores espaçamento entrelinhas $(0,40$; $0,60 ; 0,80$ e $1,0 \mathrm{~m})$ e espaçamento entre plantas na linha $(0,30 ; 0,40$ e $0,50 \mathrm{~m})$. As unidades experimentais foram constituídas por 26 plantas distribuídas em três linhas: na linha central havia oito plantas e nas linhas adjacentes nove plantas. Para coleta de dados das características avaliadas, foram utilizadas as plantas da linha central da parcela, excluindo-se a primeira e a última planta. $\mathrm{O}$ experimento foi realizado em blocos casualizados, com três repetiçōes, em esquema fatorial $4 \times 3$.

$\mathrm{O}$ preparo do solo da área experimental foi feito com aração e gradagem. A análise química do solo, na camada de $0-20 \mathrm{~cm}$, resultou em: $\mathrm{pH}\left(\mathrm{CaCl}_{2}\right)=5,5 ;$ M.O. $=19 \mathrm{~g}$ $\mathrm{dm}^{-3} ; \mathrm{P}$ (resina) $=93 \mathrm{mg} \mathrm{dm}^{-3} ; \mathrm{K}, \mathrm{Ca}$ e $\mathrm{Mg}=2,6 ; 34$ e 13 mmol dm ${ }^{-3} ; \mathrm{H}+\mathrm{Al}, \mathrm{SB}$ e CTC $=28 ; 49,6$ e 77,6 mmol $\mathrm{dm}^{-3} ; \mathrm{V} \%=64 ; \mathrm{B}, \mathrm{Cu}, \mathrm{Fe}, \mathrm{Mn}$ e $\mathrm{Zn}=0,52 ; 3,0 ; 15 ; 42$ e $2,5 \mathrm{mg} \mathrm{dm}^{-3}$. A calagem foi realizada com calcário calcinado com PRNT de $120 \%$, para elevar a saturação por bases a $80 \%$. Na adubaçáo de plantio foram aplicados 60 $\mathrm{kg} \mathrm{ha}^{-1}$ de N, $200 \mathrm{~kg} \mathrm{ha}^{-1}$ de $\mathrm{P}_{2} \mathrm{O}_{5}$ e $180 \mathrm{~kg} \mathrm{ha}^{-1}$ de $\mathrm{K}_{2} \mathrm{O}$, não sendo utilizado esterco. $\mathrm{Na}$ adubaçáo de cobertura foi utilizada a dose de $200 \mathrm{~kg} \mathrm{ha}^{-1}$ de N e $120 \mathrm{~kg} \mathrm{ha}^{-1}$ de $\mathrm{K}_{2} \mathrm{O}$, parceladas em três vezes aos 15, 30 e 45 dias após o transplante (DAT); na primeira parcela foram aplicados $25 \%$ de $\mathrm{N}_{\text {e }} \mathrm{K}_{2} \mathrm{O}$; na segunda parcela $35 \%$ de $\mathrm{N}$ e $\mathrm{K}_{2} \mathrm{O}$, e na terceira parcela foram aplicados $40 \%$ de $\mathrm{N}$ e $\mathrm{K}_{2} \mathrm{O}$. Foram realizadas três adubaçôes foliares, aos 15, 30 e 45 dias DAT, com ácido bórico e molibdato de sódio, e em cada aplicaçáo utilizou-se 1,0 e $1,54 \mathrm{~g} \mathrm{~L}^{-1}$ de água respectivamente. A calagem e as adubaçóes de plantio e de cobertura foram baseadas na recomendaçáo de TRANI et al. (1997).

A cultivar utilizada foi a Red Jewel, híbrido $F_{1}$, do tipo roxo, uma das duas cultivares consideradas por PoRTO et al. (2007) como mais adaptadas a Jaboticabal (SP). A semeadura foi realizada em 19 de maio de 2008, em bandejas de polipropileno de 200 células. As mudas foram plantadas em 3 de julho de 2008, quando estavam com quatro folhas. A irrigação, via aspersão, foi feita com aspersores ZE-30D da Asbrasil, com bocais de 4,5 x $5,5 \mathrm{~mm}$ de diâmetro, espaçados de $12 \times 12 \mathrm{~m}$ e lâmina d'agua variável conforme a idade da planta. $\mathrm{O}$ controle das plantas daninhas foi feito por capina manual. Foram realizadas pulverizações preventivas com inseticidas para o controle de traça das crucíferas (Plutella xylostella), vaquinha (Diabrotica speciosa), pulgão (Brevicoryne brassicae) e mosca-branca (Bemisia argentifoli) e com fungicidas para o controle de Alternariose (Alternaria spp.).

Foram avaliados: a) número de folhas por planta: realizado por ocasião da colheita da "cabeça"; b) área foliar: na colheita, obtida de duas plantas em medidor eletrônico 
de área foliar, marca LICOR, modelo 3100; c) índice de área foliar (IAF): obtido pela razão entre a área foliar de folhas externas à "cabeça” e a área disponível à planta; d) massa seca das folhas externas à "cabeça"; as folhas foram lavadas e secas em estufa com circulação de ar, a $65^{\circ} \mathrm{C}$, até atingir massa constante; e) massa fresca da "cabeça": após a colheita, as "cabeças" foram pesadas individualmente e obteve-se o valor médio; f) produtividade: obtida pela soma da massa da "cabeça" do repolho produzida por todas as plantas colhidas na área útil.

Foi realizada análise de variância pelo teste F, segundo o delineamento proposto, utilizando-se o programa estatístico SAS (Sas Institute, 1993). Para melhor interpretação do efeito conjunto dos fatores espaçamento entrelinhas e espaçamento entre plantas, independentemente de se ter constatado interação significativa entre eles, realizou-se o estudo de superfície de resposta polinomial quadrática. Quando houve efeito significativo (teste F, p < $0,05)$, este modelo foi utilizado para o estudo da interaçáo dos fatores estudados. Para a confecção dos gráficos de superfície de resposta, utilizou-se o programa estatístico Statistica (Statsoft, 1995).

A equação que rege a regressão polinomial múltipla na superfície de resposta de segunda ordem segue o modelo: $\mathrm{Y}=\mathrm{b}_{0}+\mathrm{b}_{1}(\mathrm{x})+\mathrm{b}_{2}(\mathrm{y})+\mathrm{b}_{3}(\mathrm{x})^{2}+\mathrm{b}_{4}(\mathrm{x})^{*}(\mathrm{y})+\mathrm{b}_{5}(\mathrm{y})^{2}$, sendo: $\mathrm{b}_{0}=$ intercepto; $\mathrm{b}_{1}=$ coeficiente linear para o espaçamento entrelinhas; $b_{2}=$ coeficiente linear para o espaçamento en- tre planta; $b_{3}=$ coeficiente quadrático para o espaçamento entrelinhas; $b_{4}=$ coeficiente da interação entre os fatores espaçamento entrelinhas e entre planta e $b_{5}=$ coeficiente quadrático para o espaçamento entre planta.

\section{RESULTADOS E DISCUSSÃO}

O número de folhas (NF), a área foliar (AF), a massa seca de folhas (MSF) da planta de repolho, cultivar Red Jewel, o índice de área foliar (IAF) da cultura e a massa fresca da "cabeça" (MFC) foram influenciados significativamente pelos fatores isolados (Tabela 1) e houve ajustes significativos da superfície de resposta para as características (Tabela 2).

Verificou-se aumento do NF, da AF e da MSF com incrementos nos espaçamentos entrelinhas e entre plantas na linha. Para NF, esses aumentos foram proporcionais aos dois fatores até $0,40 \mathrm{~m}$ e $0,60 \mathrm{~m}$ entre plantas e entrelinhas, respectivamente. A partir de então, os incrementos percebidos quando se aumentou o espaçamento entre plantas foram maiores do que os observados com o aumento entre as linhas. Esse aumento também foi observado para $\mathrm{AF}$.

Os máximos valores de NF (14 folhas) e AF (7.701 $\mathrm{cm}^{2}$ planta $\left.^{-1}\right)$ foram obtidos com $0,82 \times 0,50 \mathrm{~m}$ e $0,90 \mathrm{x}$ $0,50 \mathrm{~m}$, respectivamente (Figuras 1 e 2). Seus máximos

Tabela 1. Valores de F, significâncias e coeficientes de variaçâo das características número de folhas (NF), área foliar (AF), massa seca de folhas (MSF), índice de área foliar (IAF), massa fresca da "cabeça” (MFC) e produtividade (PROD) do repolho roxo 'Red Jewel'. Jaboticabal (SP), 2008

\begin{tabular}{lccccccc} 
Causas de variação & NF & AF & MSF & IAF & MFC & PROD \\
\hline EL & $5,46^{* *}$ & $16,57^{* *}$ & $18,90^{* *}$ & $50,63^{* *}$ & $22,59^{* *}$ & $11,83^{* *}$ \\
\hline EP & $11,13^{* *}$ & $5,69^{*}$ & $23,08^{* *}$ & $32,87^{* *}$ & $21,75^{* *}$ & $0,61^{\text {NS }}$ \\
\hline EL x EP & $0,65^{\text {NS }}$ & $0,88^{\text {NS }}$ & $1,48^{\text {NS }}$ & $0,51^{\text {NS }}$ & $0,23^{\text {NS }}$ & $0,92^{\text {NS }}$ \\
\hline CV $(\%)$ & 6,14 & 10,48 & 9,75 & 10,12 & 15,01 & 14,95
\end{tabular}

$\mathrm{EL}=$ Entrelinhas, $\mathrm{EP}=$ Entre plantas; ${ }^{* *}$ significativo a $1 \%$ de probabilidade pelo teste $\mathrm{F} ;{ }^{*}$ : significativo a $5 \%$ de probabilidade pelo teste $\mathrm{F} ;{ }^{\text {ns }}$ : năo significativo a $5 \%$ de probabilidade pelo teste $\mathrm{F}$.

Tabela 2. Análises de superfícies de resposta para as características número de folhas (NF), área foliar (AF), massa seca de folhas (MSF), índice de área foliar (IAF), massa fresca da "cabeça” (MFC) e produtividade (PROD) do repolho roxo 'Red Jewel', Jaboticabal (SP), 2008

\begin{tabular}{|c|c|c|c|c|c|c|}
\hline Parâmetros do modelo & NF & AF & MSF & IAF & MFC & PROD \\
\hline$b_{0}$ & 1,0885 & $-3803,6460$ & $-55,8546$ & 7,5087 & $-1509,9740$ & 1,0778 \\
\hline $\mathrm{b}_{1}$ & 11,9278 & 16933,0000 & 271,0594 & $-3,2742$ & 44440,9215 & 11,0192 \\
\hline$b_{2}$ & 29,9695 & 13438,0000 & 27,7042 & $-10,5700$ & 2067,9752 & 2,1518 \\
\hline$b_{3}$ & $-6,2569$ & $-6197,7152$ & $-133,5627$ & 1,1944 & $-2490,2983$ & $-6,9860$ \\
\hline $\mathrm{b}_{4}$ & $-3,3498$ & $-11865,0000$ & $-143,4748$ & $-2,1003$ & $-232,3748$ & $-8,5415$ \\
\hline$b_{5}$ & $-25,1663$ & 380,7075 & 202,1238 & 9,5835 & 318,7913 & 3,1225 \\
\hline Teste F para o modelo & $6,19^{*}$ & $40,43^{* *}$ & $28,50^{* *}$ & $109,14^{* *}$ & $38,90^{* *}$ & $6,12^{* *}$ \\
\hline $\mathrm{R}^{2}$ & 0,84 & 0,97 & 0,96 & 0,99 & 0,97 & 0,84 \\
\hline CV(\%) & 3,80 & 3,42 & 4,88 & 3,69 & 6,50 & 9,26 \\
\hline
\end{tabular}


foram superiores em três folhas e em $3.150 \mathrm{~cm}^{2}$ aos mínimos obtidos para ambas as características quando foi adotado os menores espaçamentos entrelinhas e entre plantas, $0,40 \times 0,30 \mathrm{~m}$. Ou seja, reduções no NF e na AF foram tanto maiores quanto menor foi o espaçamento en-

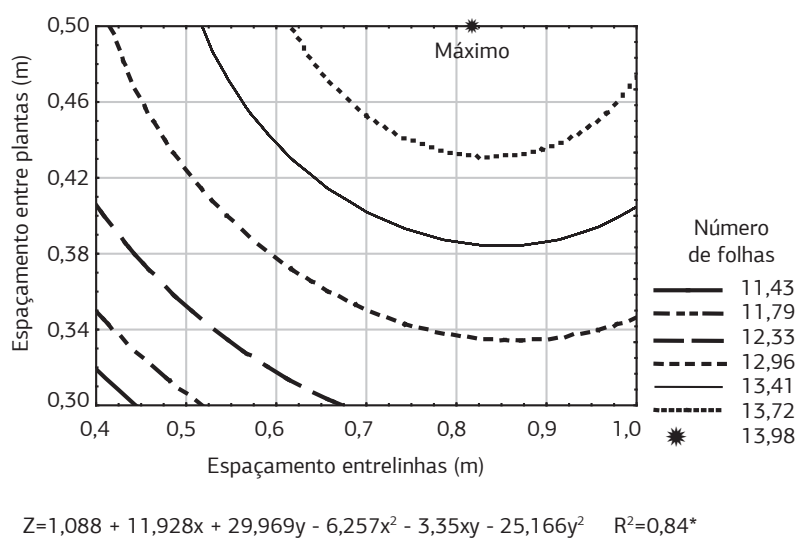

Figura 1. Isolinhas da superfície de resposta para número de folhas de repolho roxo 'Red Jewel', em funçáo do espaçamento entrelinhas e entre plantas, Jaboticabal (SP).

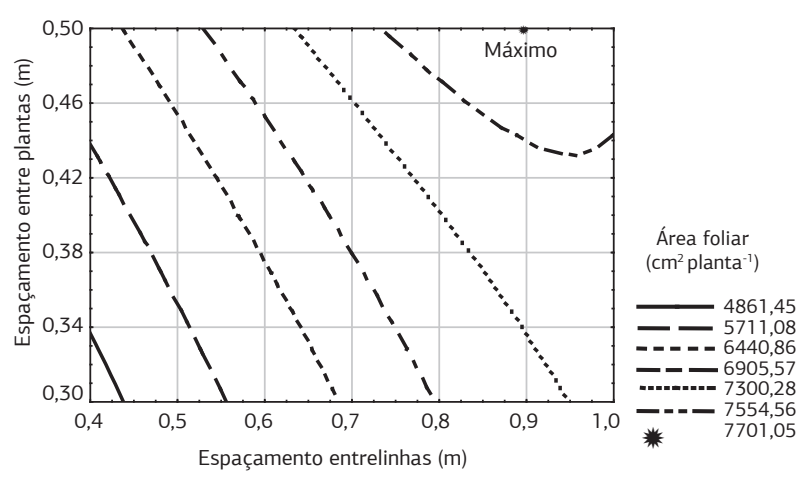

$Z=-3803,646+16922,45 x+13438,3 y-6197,714 x^{2}-11864,97 x y-380,713 y^{2} \quad R^{2}=0,97^{* *}$

Figura 2. Isolinhas da superfície de resposta para área foliar $\left(\mathrm{cm}^{2}\right.$ planta $\left.^{-1}\right)$ de repolho roxo 'Red Jewel', em função do espaçamento entrelinhas e entre plantas, Jaboticabal (SP).

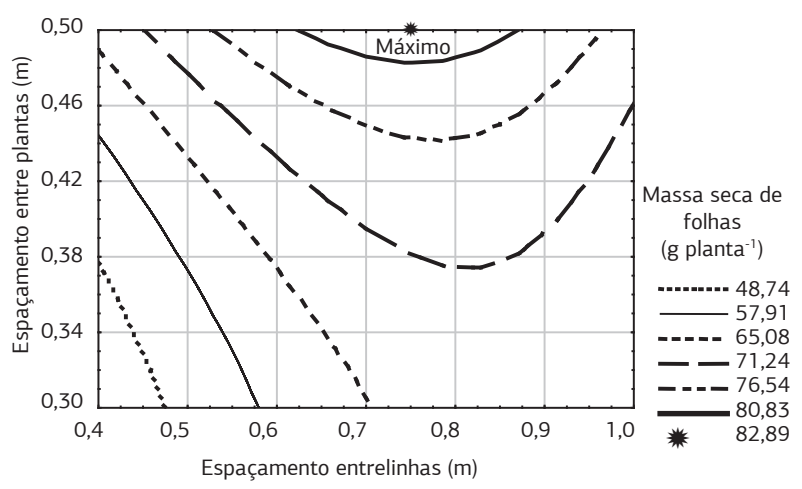

$Z=-55,855+271,059 x+27,740 y-133,563 x^{2}-143,475 x y-202,1242 y^{2} \quad R^{2}=0,96^{* *}$

Figura 3. Isolinhas da superfície de resposta para massa seca de folhas (g planta $\left.{ }^{-1}\right)$ de repolho roxo 'Red Jewel', em função do espaçamento entrelinhas e entre plantas, Jaboticabal (SP). tre plantas e entrelinhas. Estes resultados corroboram com os constatados por CAVARIANNI (2008), com a cultivar Red Jewel, o qual observou que plantas na menor população (31.250 plantas ha-1) tinham duas folhas a mais por planta (14,3 folhas planta $\left.{ }^{-1}\right)$ do que na maior densidade de plantas (46.875 plantas ha $^{-1}$ ). Embora TAKEISHI et al. (2008) trabalharam com arranjamento distinto daquele utilizado neste trabalho, quando se considera a populaçáo de 43.500 plantas $\mathrm{ha}^{-1}$, verifica-se que a $\mathrm{AF}$ obtida para a 'Red Jewel' neste trabalho $\left(6.486 \mathrm{~cm}^{2}\right.$ planta $\left.{ }^{-1}\right)$ foi semelhante à verificada por aqueles autores $\left(6.620 \mathrm{~cm}^{2}\right.$ planta $^{-1}$ ) com a mesma cultivar.

As reduçóes do número de folhas e da área foliar da planta podem ser explicadas pela maior competição entre plantas de repolho por espaço e fatores de crescimento, principalmente, luminosidade. Muito provavelmente, ocorreu maior sobreposição de folhas de plantas adjacentes, com reflexo negativo sobre a fotossíntese líquida e, consequentemente, sobre o crescimento. Os resultados observados concordam com os de Araújo (1975), Stoffella e Fleming (1990), Aquino et al. (2005) e CavaRIANNI (2008).

A máxima massa seca de folhas (MSF), 82,9 $\mathrm{g} \mathrm{planta}^{-1}$, foi obtida com $0,75 \times 0,50 \mathrm{~m}$, enquanto a menor $(40,5$ $\mathrm{g}_{\text {planta }}{ }^{-1}$ ) foi obtida com 0,40 x 0,30 m (Figura 3), ou seja, na maior densidade de plantio, assim como também constatado para NF e AF. O resultado concorda com o obtido por CAVARIANNI (2008), que observou maior massa seca da parte aérea da cultivar Red Jewel na cultura menos adensada (31.250 plantas ha $\left.{ }^{-1}\right)$ e quando foi satisfeita a demanda de nitrogênio.

Quanto ao IAF, o menor índice foi de 1,49, obtido no espaçamento de $1,00 \mathrm{~m}$ nas entrelinhas e $0,50 \mathrm{~m}$ entre plantas; o máximo IAF foi de 3,83 quando o espaçamento entrelinhas foi de $0,40 \mathrm{~m}$ e entre plantas, de $0,30 \mathrm{~m}$ (Figura 4). Então, tem-se que o IAF máximo foi $157 \%$ maior do que o menor valor observado. No entanto, não se trata, simplesmente, de elevar o IAF. Este deve ser avaliado de modo a retratar a melhor combinação de espaçamentos entrelinhas e entre plantas, associada aos demais fatores do manejo cultural e ambiente, para maximizar economicamente o cultivo. De acordo com LARCHER (2000), quando há aumento do índice de área foliar, há maior disponibilidade de superfície fotossinteticamente ativa, podendo ocorrer aumento da taxa de produçáo de maneira correspondente. Esse processo realmente ocorre quando os valores do IAF são baixos e pode-se elevar a população de plantas. Contudo, quando as plantas estáo muito próximas umas das outras, há intenso autossombreamento das superfícies de assimilação e a interceptação da radiação pela folhagem, em muitos pontos, não é mais suficiente para manter um balanço positivo de carbono, como consequência, a produção diminui. Explica-se porque o espaçamento que proporcionou o maior IAF não foi o mesmo em que se verificaram os maiores valores de 
NF, AF e MSF. Ao contrário, no maior IAF, os valores das características que descrevem o crescimento da cultivar Red Jewel foram mínimos.

A massa fresca de "cabeça" (MFC) foi influenciada significativamente pelos fatores isoladamente (Tabela 1). Porém, houve ajuste significativo da superfície de resposta para MFC (Tabela 2). A máxima MFC, $1481 \mathrm{~g}$, foi atingida com $0,87 \mathrm{~m}$ entrelinhas e $0,50 \mathrm{~m}$ entre plantas e IAF 1,76 (Figura 5). Žnidarčıč et al. (2007) também verificaram que no maior espaçamento entre plantas, o repolho teve a massa da "cabeça" aumentada.

A menor massa fresca da "cabeça" (MFC), 489,15 $\mathrm{g}$, foi obtida no menor espaçamento entrelinhas e entre plantas, 0,40 x 0,30 m, com IAF de 3,83. Esses repolhos estavam muito bem formados, compactos e sem defeitos; embora sejam pequenos, têm condiçóes de serem comercializados, uma vez que a tendência do mercado atualmente é por hortaliças de menores dimensôes, pois o número de componentes familiares tem diminuído.

O resultado observado para MFC expressa o efeito negativo que o adensamento teve sobre o NF, AF e MSF. As isolinhas que descrevem a MFC em função dos espaçamentos avaliados (Figura 5) assemelham-se às observadas para MSF. Nota-se que, assim como observado para MSF, a MFC teve contribuiçôes cada vez menores do espaçamento entrelinhas à medida que maior foi o espaçamento entre plantas. Este resultado está de acordo com Castro et al. (1987), quando afirmam que a redução do espaçamento entre plantas conduz à maior competição pelos fatores de crescimento, fazendo com que estas permaneçam menores, associado ao menor espaço físico disponível limitando a expansão foliar. Máximos obtidos para NF, MSF, AF e MFC foram verificados com espaçamento entre plantas de $0,50 \mathrm{~m}$, enquanto os espaçamentos entrelinhas foram de 0,$82 ; 0,75 ; 0,90 \mathrm{e}$ $0,87 \mathrm{~m}$, respectivamente, muito próximos, especialmente NF, AF e MFC.

Mantendo-se 0,50 $\mathrm{m}$ entre plantas e reduzindo-se o espaçamento entrelinhas de $0,875 \mathrm{~m}$ para $0,675 \mathrm{~m}$, a MFC diminui de $1,48 \mathrm{~kg}$ para $1,39 \mathrm{~kg}$, apenas $90 \mathrm{~g}$. Por outro lado, tem se um aumento de 6.772 plantas ha ${ }^{-1}$. Esse manejo pode ser interessante economicamente para o produtor, pois a pequena redução na massa do repolho é compensada pelo grande aumento da populaçáo de plantas e repolhos colhidos, proporcionando incremento da produtividade de $7.356,6 \mathrm{~kg} \mathrm{ha}^{-1}$.

A produtividade (PROD) foi influenciada significativamente pelo fator espaçamento entrelinhas (Tabela 1). Houve ajuste significativo da superfície de resposta para PROD em funçáa dos espaçamentos entrelinhas e entre plantas (Tabela 2). A maior PROD $\left(4,56 \mathrm{~kg} \mathrm{~m}^{-2}\right)$ foi observada no espaçamento $0,60 \mathrm{~m}$ entrelinhas e $0,30 \mathrm{~m}$ entre plantas, enquanto a menor $\left(2,70 \mathrm{~kg} \mathrm{~m}^{-2}\right)$ foi obtida com 1,00 x 0,50 m (Figura 6), cerca de 69\% maior. Mesmo com reduçóes no NF, AF, MSF e MFC, à medida que maior foi a população, a PROD cresceu, pois houve uma compensação da menor massa da "cabeça" pelo aumento do número de plantas na área. As isolinhas da figura 6 permitem visualizar que a PROD foi incrementada com o aumento do espaçamento das entrelinhas até $0,60 \mathrm{~m}$ e com

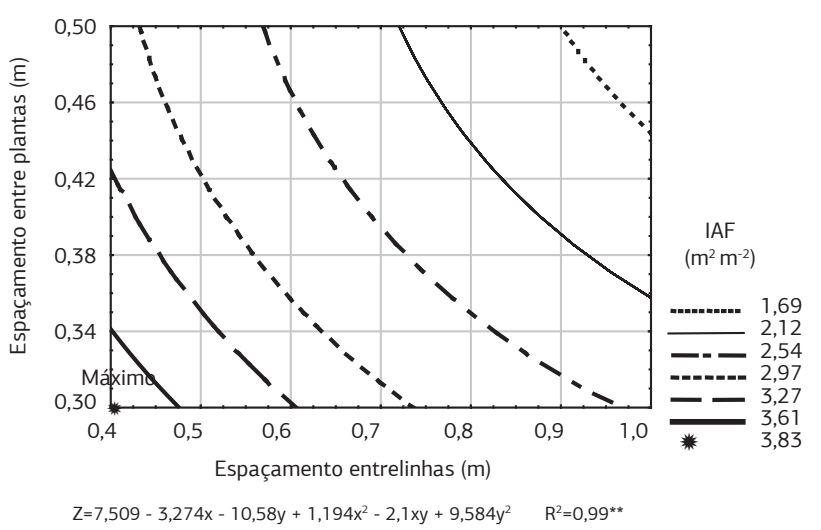

Figura 4. Isolinhas da superfície de resposta para índice de área foliar (IAF) de repolho roxo 'Red Jewel', em função do espaçamento entrelinhas e entre plantas. Jaboticabal (SP).

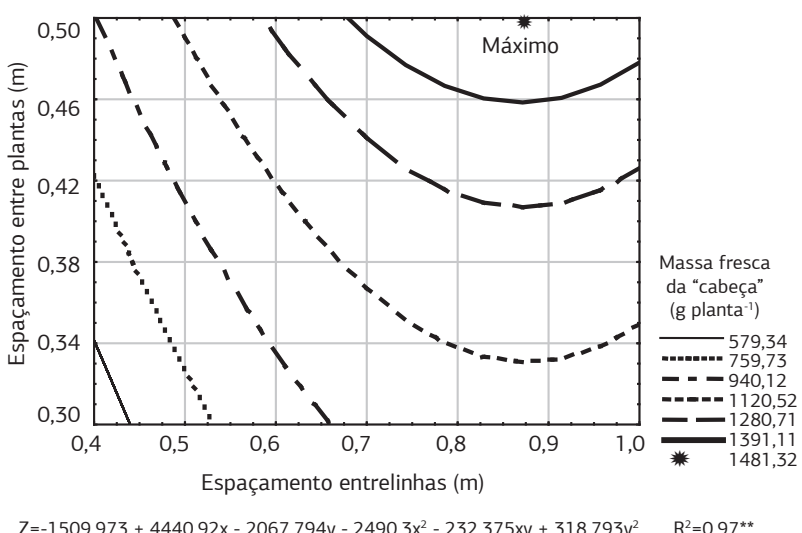

Figura 5. Isolinhas da superfície de resposta para massa fresca da "cabeça" (g planta ${ }^{-1}$ ) de repolho roxo 'Red Jewel', em função do espaçamento entrelinhas e entre plantas, Jaboticabal (SP).

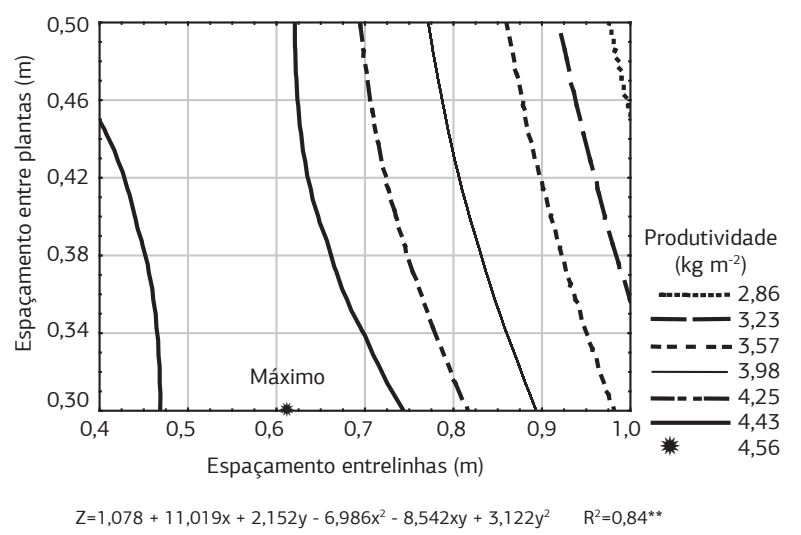

Figura 6. Isolinhas da superfície de resposta para produtividade $\left(\mathrm{kg} \mathrm{m}^{-2}\right)$ de repolho roxo 'Red Jewel', em função do espaçamento entrelinhas e entre plantas, Jaboticabal, SP. 
a diminuiçáo no espaçamento entre plantas. $\mathrm{O}$ aumento no espaçamento entrelinhas superior a $0,60 \mathrm{~m}$ causou reduçóes na PROD. O efeito do espaçamento entrelinhas foi marcante na PROD. Conforme a Figura 6, maiores espaçamentos entrelinhas reduziram a PROD para um mesmo espaçamento entre plantas. STOFFELla e Fleming (1990) também verificaram que a PROD foi reduzida à medida que maior foi o espaçamento entre plantas. CAVARIANNI (2008) também verificou que maior população (46.875 plantas ha $\left.^{-1}\right)$ proporcionou maior PROD (23,8 $\left.\mathrm{t} \mathrm{ha}^{-1}\right)$ de repolho roxo, cultivar Red Jewel, enquanto na menor população (31.250 plantas ha ${ }^{-1}$ ) a PROD foi de $17,5 \mathrm{t} \mathrm{ha}^{-1}$.

A MFC, MSF e AF foram de $879 \mathrm{~g}_{\text {planta }}{ }^{-1}, 60 \mathrm{~g}$ planta $^{-1}$ e $6.045 \mathrm{~cm}^{2}$ planta $^{-1}$ quando a PROD foi máxima no espaçamento $0,60 \times 0,30 \mathrm{~m}$. O IAF para a máxima produtividade foi de 3,26 , muito maior do que o índice que proporcionou a máxima MFC. Há de se avaliar se a redução substancial na MFC de $1.481 \mathrm{~g}$ (máxima MFC, obtida com $0,87 \mathrm{~m}$ entrelinhas e $0,50 \mathrm{~m}$ entre plantas) para 879 g (obtida no espaçamento que proporcionou a máxima produtividade) não compromete economicamente o cultivo, haja vista a valoração do repolho levar em consideração o seu tamanho (massa).

Os resultados observados para incremento de produtividade em decorrência do adensamento populacional, demonstram que o ponto de máxima competiçáo entre plantas da cultura não foi atingido. Consequentemente, incremento na produtividade pode ser obtido com maiores populações, devendo-se, contudo, levar em consideração o tamanho e as características qualitativas que podem restringir a comercialização.

\section{CONCLUSÕES}

A redução nos espaçamentos entrelinhas e entre plantas de repolho 'Red Jewel', com consequente aumento na densidade populacional, causa reduçóes no número de folhas, na área foliar, massa seca de folhas e massa fresca da "cabeça".

A produtividade de repolho 'Red Jewel' aumenta com a diminuiçáo dos espaçamentos, sendo mínima em $1,0 \mathrm{x}$ $0,50 \mathrm{~m}$ (20.000 plantas ha $\left.{ }^{-1}\right)$ e máxima com 0,60 x 0,30 $\mathrm{m}\left(54.644\right.$ plantas $\left.\mathrm{ha}^{-1}\right)$.

O manejo do espaçamento propicia ao produtor elevar a produtividade da cultura e adequar o tamanho (massa) do repolho às exigências do mercado.

\section{AGRADECIMENTOS}

À Coordenação de Aperfeiçoamento de Pessoal de Nível Superior (CAPES) pelo apoio financeiro ao projeto de pesquisa.

\section{REFERÊNCIAS}

AQUINO, L.A.; PUIATTI, M.; PEREIRA, P.R.G.; PEREIRA, F.H.F.; LADEIRA, I.R.; CASTRO, M.R.S. Efeito de espaçamento e doses de nitrogênio sobre as características qualitativas da produçáo do repolho. Horticultura Brasileira, v.23, p.100-104, 2005.

ARAÚJO, L.C.P. Efeitos de população de plantas em cultivares de repolho de verão (Brassica oleracea, var. capitata, L.). 1975. 71f. Dissertação (Mestrado em Fitotecnia) - Escola Superior de Agricultura "Luiz de Queiroz", Universidade de São Paulo, Piracicaba.

CASTRO, P.R.C.; FERREIRA, S.O.; YAMADA, T. Ecofisiologia da produçáo agrícola. Piracicaba: Associaçáo Brasileira para Pesquisa da Potassa e do Fosfato, 1987. 249p.

CAVARIANNI, R.L. Densidades de plantio e doses de nitrogênio no desenvolvimento e produção de repolho. 2008. 111f. Tese (Doutorado em Agronomia) - Faculdade de Ciências Agrárias e Veterinárias, Universidade Estadual Paulista, Jaboticabal.

CHOAIRY, S.A.; FERNANDES, P.D. Densidade de plantio na cultura do abacaxi. Pesquisa Agropecuária Brasileira, v.18, p.985988, 1983.

LARCHER, W . Ecofisiologia vegetal. São Carlos: RiMa , 2000. 531p.

MENDOZA, J.F.B. Efeitos de poda e população de tomate (Lycopersicon esculentun Mill). In: MULLER, J.J.V.; CASALI, V.W.D. (Ed.). Seminários de olericultura. Viçosa: UFV, 1982. v. 4, p. 122-140.

PORTO, D.R.Q.; CECÍlIO FILHO, A.B.; REZENDE, B.L.A.; BARROS JÚNIOR, A.P.; FELTRIM, A.L.; SILVA, G.S. Avaliação de cultivares de repolho roxo na primavera-verão de Jaboticabal-SP. In: Congresso Brasileiro de Olericultura, 47., 2007, Porto Seguro. Anais... Campinas: Associação Brasileira de Horticultura, 2007.

SAS INSTITUTE. SAS/STAT: user's guide, version 6. 2 . $^{\text {nd }} \mathrm{ed}$. Cary, NC: SAS Institute, 1993. 1022p.

STATSOFT. Statistica for Windows - computer program manual. Tulsa, UK: StatSoft, 1995.

STOFFELLA, P.J.; FLEMING, M.F. Plant population influences yield variability of cabbage. Journal of the American Society for Horticultural Science, v.115, p.708-711, 1990.

TAKEISHI, J.; CECÍLIO FILHO, A.B.; BARROS JÚNIOR, A.P.; SILVA, G.S. Desempenho de cultivares de repolho roxo nas estaçóes de outono-inverno e primavera-verão. In: Congresso Brasileiro de Olericultura, 48., 2008, Maringá. Anais... Campinas: Associação Brasileira de Horticultura, 2008.

TRANI, P.E.; PASSOS, F.A.; AZEVEDO FILHO, J.A.; TAVARES, M. Repolho. In: RAIJ, B.van; CANTARELLA, H.; QUAGGIO, J.A.; FURLANI, A.M.C. Recomendações de adubação e calagem para o Estado de São Paulo. Campinas: IAC, 1997. 175p.

ŽNIDARČIČ, D.; KACJAN-MARŠIĆ, N.; OSVALD, J.; POŽRL, T.; TRDAN, S. Yield and quality of early cabbage in response to within-row plant spacing. Acta Agriculturae Slovenica, v.89, p.1523, 2007. 